\title{
Herança de caracteres de resistência por antixenose de Solanum pennellii à traça-do-tomateiro em cruzamento com 'Santa Clara'
}

\author{
Gisele R Moreira' ${ }^{\text {; }}$ Derly José H da Silva²; Pedro CS Carneiro²; Marcelo C Picanço²; Aline de A Vascon- \\ celos $^{2}$; Cleide Maria F Pinto ${ }^{3}$ \\ 'UFES-CCA, C. Postal 16, 29500-000 Alegre-ES; gisele.moreira@ufes.br; ²UFV, 36571-000 Viçosa-MG; derly@ufv.br; carneiro@ufv.br;

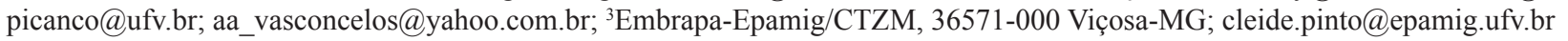

\section{RESUMO}

Com o objetivo de estudar a herança de caracteres de resistência do tipo antixenose à traça-do-tomateiro foram avaliadas populações $\mathrm{F}_{2}$ e de retrocruzamento, bem como gerações parentais, em cruzamento entre Solanum lycopersicum cv. Santa Clara e S. pennellii (LA 716). Foram avaliados o número de ovos por folha, número de minas pequenas, número de minas grandes e número total de minas. O estudo de herança foi realizado por meio das análises das variâncias e das médias. Há indicativo de herança poligênica no controle do número de ovos por folha, número de minas grandes e número total de minas. Com base nas médias há dominância parcial para maior número de ovos por folha e maiores números de minas pequenas, grandes e totais. Tanto o modelo completo quanto o aditivo-dominante são apropriados ao estudo da herança do número de minas pequenas e número total de minas, sendo o efeito aditivo o mais importante na determinação dos caracteres de resistência. O número total de minas, como caráter de resistência à traça-do-tomateiro é importante em programas de melhoramento que visam à obtenção de variedade de tomate resistente em cruzamento de 'Santa Clara' x LA 716.

Palavras-chave: Solanum spp., Tuta absoluta, controle genético, recursos genéticos.

\begin{abstract}
Inheritance of antixenosis character resistance of Solanum pennellii to tomato leafminer in crossing with 'Santa Clara'

The inheritance of antixenosis resistance characters to Tuta absoluta populations $\mathrm{F}_{2}$ and backcrosses and parental generations were evaluated on crossings involving Solanum lycopersicum cv. Santa Clara and S. pennellii (LA 716). The characters number of eggs per leaf, number of small mines, number of large mines and total number of mines were evaluated. There is indicative of polygenic inheritance in controlling the number of eggs per leaf, number of large mines and the total number of mines. Based on averages there is partial dominance for higher number of eggs per leaf, number of small mines, number of large mines and total number of mines. Both the complete model and the additive-dominant are appropriate to the study of the inheritance of the number of small mines and the total number of mines, the additive effect being the most important in determining the character of resistance. The total number of mines, as the character of resistance to tomato leafminer is important in breeding programs that aim to obtain a resistant variety from crossing between 'Santa Clara' x LA 716.
\end{abstract}

Keywords: Solanum spp., Tuta absoluta, genetic control, genetic resources.

\section{(Recebido para publicação em 24 de outubro de 2012; aceito em 10 de outubro de 2013)}

(Received on October 24, 2012; accepted on October 10, 2013)

$\mathrm{O}$ tomateiro (Solanum lycopesicum) destaca-se como uma das hortaliças mais cultivadas mundialmente, superada apenas pela batata. Segundo dados do AGRIANUAL (2012), no ano de 2009, os maiores produtores mundiais foram China, EUA e Índia, com produção de 45.365.543, 14.141 .900 e 11.148 .800 toneladas, respectivamente. O Brasil ocupa a nona posição, correspondendo a cerca de 3\% da produção mundial. Aárea colhida com tomate em 2009 no Brasil foi 67.605 hectares, correspondendo a uma produção de 4.310 .480 toneladas. As maiores produções estão nos estados de Goiás, São Paulo e Minas Gerais, com $1.405 .996,672.030$ e 477.921 toneladas, respectivamente.
O tomateiro pode sofrer danos causados por diversos patógenos e pragas durante o seu ciclo de produção. No contexto das pragas consta a traça-do-tomateiro, Tuta absoluta (Meyrick) (Lepidoptera: Gelechiidae), cujos danos são caracterizados por galerias produzidas pelas lagartas nas folhas, ramos e principalmente nas gemas apicais, onde destroem as brotações novas, além dos frutos que são depreciados para a comercialização (Gallo et al., 2002; Medeiros et al., 2009).

A traça-do-tomateiro é considerada praga-chave do tomateiro, não somente pela intensidade que ocorre e pelos prejuízos causados, mas também pela dificuldade de controle. O principal método de controle é a aplicação de inseticidas, entretanto, o uso frequente afeta os inimigos naturais e aumenta a possibilidade de desenvolvimento de populações da praga resistentes aos inseticidas, além da produção de alimentos com altos níveis de resíduos tóxicos (Liettii et al., 2005; Silva et al., 2011).

De modo a minimizar os problemas advindos do controle químico e manter as populações da praga abaixo do nível de dano econômico, tem-se utilizado o Manejo Integrado de Pragas (MIP), com destaque para o método de Resistência de Plantas, o qual tem as vantagens de não provocar danos ao meio ambiente, 
não implicar em ônus adicional ao agricultor, ser de fácil utilização, em razão de não interferir nas demais práticas culturais e de normalmente ser compatível com outros métodos de controle (Gallo et al., 2002).

Programas de melhoramento vêm sendo desenvolvidos com o objetivo de obter variedade de tomateiro resistente à traça-do-tomateiro. Tal resistência tem sido constatada basicamente em espécies silvestres, sendo necessária portanto, a transferência desta para o tomateiro cultivado. Dentre as espécies silvestres pertencentes ao gênero Lycopersicon (atualmente reclassificado para Solanum) têm se destacado como fontes de resistência às pragas: $L$. hirsutum f. glabratum (PI 134417) (Aragão et al., 2002), L. hirsutum f. hirsutum (PI 127826) (Azevedo et al., 2003), L. hirsutum f. typicum (PI 126445 e LA 1777) (Ecole et al., 2000; Moreira et al., 2005) e $L$. pennellii (LA 716) (Resende et al., 2006). Os mecanismos de resistência envolvidos são basicamente a antibiose e a antixenose, os quais promovem respectivamente, efeitos negativos na biologia e comportamento do inseto.

Apesar da detecção de importantes fontes de resistência à traça-do-tomateiro, os programas de melhoramento que visam incorporar tal resistência no tomateiro cultivado têm obtido sucesso limitado. Ainda não está disponível no mercado cultivar de tomate com nível satisfatório de resistência, e esta limitação pode estar relacionada a fatores como necessidade de maior entendimento da genética da resistência, interações entre as causas da resistência e dificuldade na transferência das características de resistência das espécies silvestres para a cultivada.

A dificuldade na transferência das características de resistência à traça-dotomateiro das espécies silvestres para o tomateiro cultivado pode ser reduzida a partir da identificação de genitores e de combinações híbridas promissoras em programas de melhoramento que visam aumentar a resistência a esta praga. Neste âmbito, Suinaga et al. (2004) identificaram o acesso LA 716 de L. pennellii como importante genitor a ser utilizado em programas de melhoramento que visam incorporar resistência a $T$. absoluta no tomateiro cultivado. Estes autores também identificaram a combinação 'Santa Clara' x LA 716 com alto potencial de gerar híbridos superiores.

A resistência do acesso LA 716 de L. pennellii às pragas tem sido atribuída à presença de tricomas glandulares tipo IV e fitoquímicos, denominados acilaçúcares, secretados por eles, os quais conferem efeito deterrente na oviposição e alimentação dos insetos (Gonçalves Neto et al., 2010).

Lemke \& Mutschler (1984) estudaram a herança dos tricomas glandulares tipo IV em cruzamentos de L. esculentum com L. pennellii e observaram que a presença ou ausência desses tricomas possui herança simples, sendo controlada, por no máximo, dois genes não ligados com epistasia dominante dupla. Resende et al. (2002) e Gonçalves et al. (2007), por sua vez, constataram que altos teores de acilaçúcares também se devem à ação de um alelo recessivo com dominância incompleta no sentido de altos teores.

Mutschler et al. (1996), avaliando população $\mathrm{F}_{2}$ derivada do cruzamento entre L. esculentum (New Yorker) e $L$. pennellii (LA 716) identificaram cinco regiões genômicas, duas no cromossomo 2 e uma em cada um dos cromossomos 3,4 e 11, associadas com um ou mais aspectos da produção dos acilaçúcares. Estes autores observaram também que, nas regiões dos cromossomos 2 e 11 , o alelo em $L$. esculentum foi parcialmente dominante ao alelo em L. pennellii, mas recessivo a este na região do cromossomo 3. As análises das gerações parentais, $\mathrm{F}_{1}$ e $\mathrm{F}_{2}$ indicaram a possibilidade de um gene de efeito maior com recessividade para altos teores de acilglicose.

Lowson et al. (1997) utilizaram os resultados obtidos por Mutschler et al. (1996) em um programa de melhoramento assistido por marcadores, visando incorporar o caráter produção de acilaçúcares no tomateiro cultivado e, as cinco regiões genômicas identificadas por Mutschler et al. (1996) também foram detectadas em plantas selecionadas $\mathrm{RC}_{1}$, cuja concentração de acilaçúcares foi similar à das plantas da geração $\mathrm{F}_{1}$ (concentração intermediária entre os genitores). Todavia, plantas $\mathrm{RC}_{3}$, contendo três a cinco das regiões genômicas, apresentaram menores concentrações de acilaçúcares que as plantas da geração $F_{1}$, indicando que outra região, não identificada, é necessária para acúmulo de altos teores de acilaçúcares.

Blauth et al. (1998), avaliando as gerações $\mathrm{F}_{1}, \mathrm{~F}_{2}$ e de retrocruzamentos, a partir de L. pennellii LA 716 x L. pennellii LA 1912 (níveis de acilaçúcares que variam de indetectável a aproximadamente 15\% da concentração de L. pennellii LA 716), identificaram 3 loci associados às maiores densidade de tricomas tipo IV e concentração de acilaçúcar. Todavia, um loco associado ao aumento da concentração de acilaçúcar esteve associado à diminuição da densidade de tricoma tipo IV e 3 loci estiveram associados ao aumento da concentração de acilaçúcar, porém sem nenhum efeito sobre a densidade de tricomas.

Nota-se que, embora os fatores e causas da resistência às pragas em $S$. pennellii LA 716 sejam bem relatados, os estudos realizados não evidenciam consenso sobre o tipo de herança dos tricomas glandulares tipo IV e teor de acilaçúcares, se monogênica ou poligênica, havendo necessidade de mais estudos envolvendo estes caracteres, bem como estudos sobre outros caracteres relacionados com a resistência deste acesso à traçado-tomateiro, de modo a facilitar a introgressão dessa característica no tomateiro cultivado.

Assim, objetivou-se com este trabalho ampliar os estudos da herança de caracteres de resistência do tipo antixenose à traça-do-tomateiro em cruzamento interespecífico envolvendo S. lycopersicum cv. Santa Clara e $S$. pennellii (LA 716).

\section{MATERIAL E MÉTODOS}

Foram obtidas as gerações $\mathrm{F}_{2}$, $\mathrm{RC}_{11}$ e $\mathrm{RC}_{12}$ do cruzamento entre $S$. lycopersicum cv. Santa Clara e $S$. pennellii (LA 716) com alto potencial de gerar híbridos superiores para resistência 
à traça-do-tomateiro, de acordo com Suinaga et al. (2004). As plantas foram cultivadas em condições de casa de vegetação na Horta de Pesquisa da Universidade Federal de Viçosa (UFV), Viçosa-MG, nos anos de 2003 e 2004.

A população de autofecundação $\mathrm{F}_{2}$ $\left(F_{1} \times F_{1}\right)$ foi obtida durante os meses de abril a julho de 2003, enquanto as hibridações artificiais para a obtenção das populações de retrocruzamento foram realizadas no período da manhã, durante os meses de julho a novembro do mesmo ano.

A população da traça-do-tomateiro a ser utilizada no experimento foi obtida a partir da mistura das populações provenientes de Uberlândia-MG e Santa Teresa-ES (Moreira et al., 2004) no período de 29 de outubro de 2003 a 21 de março de 2004. Vinte e quatro machos e 29 fêmeas da população de Santa Teresa e 17 machos e 43 fêmeas da população de Uberlândia (total de 41 machos e 72 fêmeas) foram colocados juntos em gaiolas de madeira $(20 \times 20 \times 20$ $\mathrm{cm}$ ), envolvidas por organza, e criados no Laboratório de Manejo Integrado de Pragas do Departamento de Biologia Animal da UFV. Essas gaiolas eram providas de aberturas por onde eram introduzidas folhas de tomateiro ('Santa Clara') cujos pecíolos permaneciam imersos em frascos contendo água. Para verificar a eficiência na multiplicação do número de insetos das populações da traça-do-tomateiro e evitar a perda de alelos por oscilação genética e/ou seleção natural, estimou-se o tamanho efetivo populacional $(\mathrm{Ne})$, considerando expressão utilizada para multiplicação de sementes de plantas dióicas com controle de gameta feminino e masculino: $N_{e}=\left(8 . N_{m} \cdot N_{f}\right)\left(N_{m}+N_{f}\right) . \quad$ E m que, $N_{m}=$ número de machos e $N_{f}=$ número de fêmeas. A partir do $\mathrm{Ne}$ estimou-se o coeficiente de endogamia, dado pela expressão: $F=1 / 2 N_{e}$.

Em 23 de março de 2004, a população mista da traça-do-tomateiro foi transferida para casa de vegetação do Depto. de Biologia Animal na UFV para obtenção do número de insetos suficiente para a infestação. Estes insetos foram criados em plantas da cultivar Santa Clara, plantadas em vasos de 3 L de capacidade, que foram dispostos sobre duas bancadas de madeira localizadas no interior da casa de vegetação.

No período de março a junho de 2004 foram obtidas simultaneamente as plantas das gerações $\mathrm{P}_{1}$ ('Santa Clara'), $\mathrm{P}_{2}$ ('LA 716'), $\mathrm{F}_{1}$ ('Santa Clara' x 'LA 716'), $F_{2}\left(F_{1} \times F_{1}\right), R_{11}$ ('Santa Clara' $x$ $\left.F_{1}\right)$ e $\mathrm{RC}_{12}\left(\mathrm{~F}_{1} \mathrm{x}\right.$ 'LA 716') na Horta de Pesquisa UFV, as quais foram cultivadas em vasos de $3 \mathrm{~L}$ de capacidade contendo a mistura terra: esterco bovino + adubo mineral (na proporção 2:1) e fumigada com brometo de metila. Foi realizado tutoramento com estacas de bambu de aproximadamente $1 \mathrm{~m}$ de comprimento, fixadas no solo verticalmente, junto a cada planta. Foi mantida uma haste por planta, sendo retiradas quatro vezes por semana as brotações excedentes.

Quando as plantas continham de seis a oito folhas definitivas foram levadas à casa de vegetação do Departamento de Biologia Animal da UFV para a infestação.

Os vasos contendo as plantas de tomate foram colocados no chão na parte central da casa de vegetação, utilizandose o delineamento inteiramente casualizado, com número de repetições correspondentes ao número de plantas por geração (tratamentos). Uma vez que não houve a possibilidade de infestar todas as plantas do experimento de uma única vez, devido ao grande número de plantas, a infestação foi feita em cinco etapas, sendo a diferença entre uma infestação e outra de dois dias (primeira infestação no dia 10/06/2004 e última no dia 18/06/2004). Nesta etapa foi avaliado o número de ovos depositados pelas fêmeas da traça-do-tomateiro por folha de cada planta.

As plantas foram avaliadas na parte da manhã do segundo dia após terem sido levadas para a casa de vegetação. $\mathrm{Na}$ parte da tarde, após terem sido avaliadas quanto à oviposição, os vasos contendo as plantas infestadas foram levados para estufa na Horta de Pesquisa da UFV e, após uma semana, iniciaram as avaliações do número de minas pequenas (comprimento $<0,5 \mathrm{~cm}$ ), número de minas grandes (comprimento $\geq 0,5 \mathrm{~cm}$ ) e número de minas totais (somatório do número de minhas pequenas e grandes), as quais foram realizadas em cada planta duas vezes por semana durante três semanas.

Os dados de número de ovos por folha, número de minas pequenas por planta, número de minas grandes por planta e número de minas totais por planta foram, inicialmente, corrigidos para o efeito relativo aos diferentes dias de infestação/avaliação.

A correção dos dados das gerações não-segregantes $\mathrm{P}_{1}, \mathrm{P}_{2}$ e $\mathrm{F}_{1}$ foi realizada obtendo-se o efeito do dia por geração por meio da média do dia subtraída da média geral em cada geração considerada, e o valor corrigido foi obtido a partir da subtração do valor original do caráter pelo efeito do dia. A correção das gerações segregantes $\mathrm{RC}_{11}, \mathrm{RC}_{12}$ e $\mathrm{F}_{2}$ foi realizada obtendo-se a média do dia com base na média das gerações $\mathrm{P}_{1}, \mathrm{P}_{2} \mathrm{e}$ $\mathrm{F}_{1}$ e subtraída da média dessas gerações em todos os dias, obtendo-se o efeito de dia. O valor corrigido para cada planta das gerações segregantes foi obtido a partir da subtração do valor original de caráter pelo efeito de cada dia em que foi avaliada.

A partir da análise das variâncias das gerações foram obtidas as seguintes estimativas: Variância fenotípica na geração $\mathrm{F}_{2}: \hat{\sigma}_{F 2}^{2}$; Variância atribuída ao meio na geração $\mathrm{F}_{2}: \hat{\sigma}_{E}^{2}=\hat{\sigma}_{P 1}^{2}$ ou $\hat{\sigma}_{P 2}^{2}$, dependendo do caráter considerado, quando se procedeu a análise dos dados corrigidos e, $\hat{\sigma}_{E}^{2}=1 / 4\left(\hat{\sigma}_{P 1_{i}}^{2}+2 \hat{\sigma}_{F 1_{i}}^{2}+\hat{\sigma}_{P 2_{i}}^{2}\right)$ quando se procedeu a análise dos dados não corrigidos; Variância genotípica: $\hat{\sigma}_{G}^{2}=$ $\hat{\sigma}_{F}^{2}-\hat{\sigma}_{E}^{2}$; Variância aditiva: $\hat{\sigma}_{A}^{2}=2 \hat{\sigma}_{F_{2}}^{2}$ - $\left(\hat{\sigma}_{R C 11}^{2}+\hat{\sigma}_{R C 12}^{2}\right)$; Variância devida aos desvios de dominância: $\hat{\sigma}_{D}^{2}=\hat{\sigma}_{G}^{2}-\hat{\sigma}_{A}^{2}$; Herdabilidade no sentido amplo:

$h_{a}^{2}=\frac{\hat{\sigma}_{G_{i}}^{2}}{\hat{\sigma}_{A}^{2}+\hat{\sigma}_{D}^{2}+\hat{\sigma}_{E}^{2}}$; Herdabilidade no sentido restrito:

$h_{r}^{2}=\frac{\hat{\sigma}_{A}^{2}}{\hat{\sigma}_{A}^{2}+\hat{\sigma}_{D}^{2}+\hat{\sigma}_{E}^{2}} ;$ Grau médio de dominância (GMD): $\mathrm{k}=\sqrt{\frac{2 \hat{\sigma}_{D}^{2}}{\hat{\sigma}_{A}^{2}}} \mathrm{e}$ número mínimo de genes envolvido na 
determinação do caráter:

$\eta=\frac{A^{2}\left(1+0,5 k^{2}\right)}{8 \hat{\sigma}_{G}^{2}}$. Em que, $\hat{\sigma}_{P 1}^{2}$,

$\hat{\sigma}_{P 2}^{2}, \hat{\sigma}_{F 1}^{2}, \hat{\sigma}_{R C 11}^{2}$ e $\hat{\sigma}_{R C 12}^{2}=$ variância fenotípica nas gerações $\mathrm{P}_{1}, \mathrm{P}_{2}, \mathrm{~F}_{1}, \mathrm{RC}_{11} \mathrm{e}$ $\mathrm{RC}_{12} \mathrm{e} \mathrm{A}=$ amplitude total na geração $\mathrm{F}_{2}$.

A análise das médias das gerações foi avaliada levando-se em conta tanto o modelo completo ( $\mathrm{m}, \mathrm{a}, \mathrm{d}, \mathrm{aa}, \mathrm{ad}, \mathrm{dd}$ ) quanto o modelo aditivo-dominante ( $\mathrm{m}, \mathrm{a}, \mathrm{d}$ ) como descrito por Cruz et al. (2004).

A análise das médias possibilitou a obtenção das seguintes estimativas:

$\hat{m}=1 / 2 \overline{P_{1}}+1 / 2 \overline{P_{2}}+4 \overline{F_{2}}-2 \overline{R C_{1}}-2$

$\overline{R C_{2}}$;

$\hat{a}=1 / 2 \overline{P_{1}}-1 / 2 \overline{P_{2}}$;

$\hat{d}=-3 / 2 \overline{P_{1}}-3 / 2 \overline{P_{2}}-\overline{F_{1}}-8 \overline{F_{2}}+6 \overline{R C_{1}}$

$+6 \overline{R C_{2}}$;

$\hat{a}=-4 \overline{F_{2}}+2 \overline{R C_{1}}+2 \overline{R C_{2}}$;

$\hat{d}=-\overline{P_{1}}+\overline{P_{2}}+2 \overline{R C_{1}}-2 \overline{R C_{2}} \mathrm{e}$

$\hat{d}=\overline{P_{1}}+\overline{P_{2}}+2 \overline{F_{1}}+4 \overline{F_{2}}-4 \overline{R C_{1}}-4$

$\overline{R C_{2}}$,

bem como o grau médio de dominância $\mathrm{GMD}=\frac{2 \overline{F_{1}}-\left(\overline{P_{1}}+\overline{P_{2}}\right)}{\overline{P_{1}}-\overline{P_{2}}}$, em que, $\overline{P_{1}}, \overline{P_{2}}$ e $\overline{F_{1}}=$ médias das gerações $\mathrm{F}_{1}, \mathrm{P}_{1}$ e $\mathrm{P}_{2}$, respectivamente.

Para testar a significância das hipóteses de que cada parâmetro é nulo $\left(\mathrm{H}_{\mathrm{o}}: \beta_{\mathrm{i}}=0\right)$, utilizou-se a estatística $\mathrm{t}$, de acordo com a seguinte expressão: $t_{\text {calc }}=\frac{\hat{\beta}_{i}-\beta_{i}}{\sqrt{\hat{V}\left(\hat{\beta}_{i}\right)}}$, cujo grau de liberdade correspondeu à soma dos graus de liberdade de cada geração envolvida na estimação do parâmetro.

Todas as análises foram realizadas com o auxílio do aplicativo computacional em genética e estatística, GENES, versão Windows (Cruz, 2013).

\section{RESULTADOS E DISCUSSÃO}

O tamanho efetivo populacional (Ne) foi estimado em 209, e o coeficiente de endogamia (F) em 0,00239 ou $0,239 \%$.

$\mathrm{O}$ conceito de tamanho efetivo populacional está relacionado à adequada representatividade genética de modo a evitar problemas com deriva genética e seleção natural, causadores de perda de alelos-raros não adaptativos; enquanto a endogamia refere-se ao aumento da homozigose ou perda da heterozigose. Segundo Valois et al. (2001), um tamanho efetivo mínimo de 50 ou mais é suficiente para que os inconvenientes citados sejam evitados, isto em processos de regeneração ou preservação de germoplasma vegetal "ex situ". Em relação aos insetos, não há na literatura referencial para que se possa afirmar o tamanho efetivo populacional ideal. Entretanto, como o valor do Ne estimado foi maior que 50, e o $\mathrm{F}$ foi baixo, pode-se inferir que a população mista da traça-do-tomateiro formada, a partir do número de insetos fêmeas e machos da população foi suficiente em manter bem próximas a variância da frequência gênica e a taxa de endogamia da população original.

$\mathrm{Na}$ Tabela 1 há as estimativas das variâncias e médias para os caracteres de resistência de planta de tomate à traça do tomateiro, bem como os graus médios de dominância (GMD) com base nos respectivos estimadores. Constatou-se que, em relação ao número de ovos por folha, a variância do $\mathrm{P}_{1}$ foi menor do que a variância do $\mathrm{P}_{2}$ e, a maior variância foi na geração $\mathrm{F}_{2}$, como esperado por ser esta a população com maior parte dos loci segregantes. A relação de menor variância em $P_{1}$ que $P_{2}$ também era esperada, uma vez que a cultivar Santa Clara é tipicamente autógama, portanto homozigota e homogênea, e a espécie silvestre $S$. pennellii (LA 716) possui reprodução sexuada por fecundação cruzada (alógama) (Taylor, 1986), portanto apresentando grande parte dos loci gênicos com genótipos em heterozigose, em elevada heterogeneidade.

Em relação aos demais caracteres, os resultados das variâncias não foram coerentes. A variância em $\mathrm{P}_{1}$ foi superior à encontrada em $\mathrm{P}_{2}$ para número de minas pequenas, grandes e totais. Para número de minas pequenas, a variância em $\mathrm{F}_{2}$ foi inferior à variância em $\mathrm{F}_{1}$, sendo a maior variância constatada na geração $\mathrm{RC}_{1}$. Para número de minas grandes e totais, a maior variância foi observada na geração $\mathrm{F}_{1}$, e a variância de $F_{2}$ foi inferior à encontrada em $P_{1}$. As estimativas do grau médio de dominância (GMD) com base nas variâncias indicaram ausência de dominância para o número de ovos por folha e número de minas grandes $(\mathrm{GMD}=0)$, e sobredominância para elevado número total de minas $(\mathrm{GMD}=$ $3,20)$.

Uma justificativa para os resultados incoerentes obtidos para as variâncias é a natureza do cruzamento interespecífico realizado. Segundo Zamir \& Tadmor (1986), citado por Gonçalves et al. (2007), o uso de acessos silvestres em cruzamentos pode provocar distorções nas proporções mendelianas, o que resulta em estimativas inconsistentes dos parâmetros genéticos. Além disso, o cruzamento realizado entre progenitores contrastantes, pressuposição para a eficiência do método (Cruz et al., 2004), envolveu a espécie silvestre S. pennellii (LA 716), tipicamente alógama, que pode ter apresentado variabilidade genotípica entre plantas para os caracteres avaliados e, em consequência, contribuindo para as estimativas viesadas das variâncias.

Outra justificativa é, possivelmente, devida ao procedimento realizado no transporte das plantas da casa-devegetação da UFV para a Horta de Pesquisa após a infestação e avaliação do número de ovos por folha. Este transporte ocorreu em cima da caçamba de um caminhão, que em contato, especialmente com o vento, pode ter provocado distorções na variável número de minas, em função de que ovos podem ter sido perdidos das plantas. Ou ainda, uma vez que a resistência de LA 716 às pragas é devida à presença de acilaçúcares exudatos pelos tricomas glandulares do tipo IV contida em toda a superfície aérea da planta e, embora os acilaçúcares sejam compostos relativamente estáveis, a ação intempérica do vento e do sol e a abrasão por partículas de poeira, ou até mesmo por folhas, reduzem drasticamente seu acúmulo nas plantas (Shapiro et al., 1994). Estes fatores podem ter contribuído para o aumento do viés nas estimativas das variâncias 
Tabela 1. Estimativas das variâncias $\left(\hat{\sigma}^{2}\right)$ e médias $(\bar{X})$ para caracteres de resistência de plantas de tomate à traça-do-tomateiro avaliados nas gerações $\mathrm{P}_{1}, \mathrm{P}_{2}, \mathrm{~F}_{1}, \mathrm{~F}_{2}, \mathrm{RC}_{11}$ e $\mathrm{RC}_{12}$ a partir do cruzamento entre 'Santa Clara' e LA 716 [estimates of variances $\left(\hat{\sigma}^{2}\right)$ and means $(\bar{X})$ for traits of resistance of tomato plants to tomato pinworm evaluated in generations $\mathrm{P}_{1}, \mathrm{P}_{2}, \mathrm{~F}_{1}, \mathrm{~F}_{2}, \mathrm{RC}_{11}$ and $\mathrm{RC}_{12}$ from crossing between Santa Clara and LA 716]. Viçosa, UFV, 2004.

\begin{tabular}{|c|c|c|c|c|c|c|c|c|c|}
\hline \multirow{3}{*}{ Geração } & \multirow{3}{*}{$\begin{array}{l}\mathrm{N}^{0} \text { de } \\
\text { plantas }\end{array}$} & \multicolumn{8}{|c|}{ Caracteres de resistência $^{1}$} \\
\hline & & \multicolumn{2}{|c|}{ NOF } & \multicolumn{2}{|c|}{ NMP } & \multicolumn{2}{|c|}{ NMG } & \multicolumn{2}{|c|}{ NTM } \\
\hline & & $\hat{\sigma}^{2}$ & $\bar{X}$ & $\hat{\sigma}^{2}$ & $\bar{X}$ & $\hat{\sigma}^{2}$ & $\bar{X}$ & $\hat{\sigma}^{2}$ & $\bar{X}$ \\
\hline $\mathrm{P}_{1}$ & 20 & 0,78 & 1,54 & 316,24 & 33,33 & 218,01 & 16,43 & 798,26 & 52,90 \\
\hline $\mathrm{P}_{2}$ & 16 & 1,05 & 0,81 & 55,47 & 3,50 & 22,17 & 3,00 & 133,37 & 6,50 \\
\hline $\mathrm{F}_{1}$ & 21 & 1,23 & 1,46 & 432,63 & 24,93 & 418,61 & 13,55 & 1001,08 & 38,50 \\
\hline $\mathrm{F}_{2}$ & 239 & 2,81 & 1,40 & 415,17 & 19,81 & 162,69 & 19,06 & 697,12 & 29,69 \\
\hline $\mathrm{RC}_{11}$ & 47 & 1,39 & 2,02 & 763,50 & 37,67 & 79,57 & 22,47 & 861,33 & 49,49 \\
\hline $\mathrm{RC}_{12}$ & 50 & 0,65 & 1,48 & 411,23 & 14,13 & 36,04 & 15,53 & 440,64 & 19,01 \\
\hline $\mathrm{GMD}^{2}$ & - & 0 & 0,78 & - & 0,44 & 0 & 0,57 & 3,20 & 0,38 \\
\hline
\end{tabular}

${ }^{1} \mathrm{NOF}=$ número de ovos por folha; $\mathrm{NMP}=$ número de minas pequenas (comprimento $\left.<0,5 \mathrm{~cm}\right) ; \mathrm{NMG}=$ número de minas grandes $($ comprimento $\geq 0,5 \mathrm{~cm}) ; \mathrm{NTM}=$ número total de minas. ${ }^{2} \mathrm{GMD}=$ grau médio de dominância estimado com base nos parâmetros genéticos obtidos das variâncias e das médias, respectivamente. 'sem valor para o GMD: cálculo impossível $\left[{ }^{1} \mathrm{NOF}=\right.$ number of eggs per leaf; $\mathrm{NMP}=$ number of small mines (length $<0,5 \mathrm{~cm}$ ); $\mathrm{NMG}=$ number of large mines (length $\geq 0,5 \mathrm{~cm}$ ); $\mathrm{NTM}=$ total number of mines. ${ }^{2} \mathrm{GMD}=$ average degree of dominance estimated based on genetic parameters obtained from the averages and variances, respectively.'without value for the GMD: calculation impossible].

Tabela 2. Estimativas dos parâmetros genéticos obtidos das variâncias para caracteres de resistência de plantas de tomate à traça-do-tomateiro avaliados nas gerações $\mathrm{P}_{1}, \mathrm{P}_{2}, \mathrm{~F}_{1}, \mathrm{~F}_{2}, \mathrm{RC}_{11}$ e $\mathrm{RC}_{12}$ a partir do cruzamento entre 'Santa Clara' e LA 716 (estimates of genetic parameters obtained from variances for traits of resistance of tomato plants to tomato pinworm evaluated in generations $\mathrm{P}_{1}, \mathrm{P}_{2}, \mathrm{~F}_{1}, \mathrm{~F}_{2}, \mathrm{RC}_{11}$ and $\mathrm{RC}_{12}$ from crossing between 'Santa Clara' and LA 716). Viçosa, UFV, 2004.

\begin{tabular}{lcccc}
\hline \multirow{2}{*}{ Parâmetros } & \multicolumn{4}{c}{ Caracteres de resistência } \\
\cline { 2 - 5 } & NOF & NMP & NMG & NTM \\
\hline Variância fenotípica $\left(\hat{\sigma}_{F 2}^{2}\right)$ & 2,81 & 415,17 & 162,70 & 697,12 \\
Variância ambiental $\left(\hat{\sigma}_{E}^{2}\right)$ & 0,78 & 55,47 & 22,17 & 133,37 \\
Variância genotípica $\left(\hat{\sigma}_{G}^{2}\right)$ & 2,03 & 359,70 & 140,53 & 563,75 \\
Variância aditiva $\left(\hat{\sigma}_{A}^{2}\right)$ & 3,58 & $-344,39$ & 209,77 & 92,26 \\
Variância de dominância $\left(\hat{\sigma}_{D}^{2}\right)$ & $-1,55$ & 704,09 & $-69,24$ & 471,49 \\
Herdabilidade no sentido amplo $\left(h_{a}^{2} \%\right)$ & 72,24 & 86,64 & 86,38 & 80,87 \\
Herdabilidade no sentido restrito $\left(h_{r}^{2} \%\right)$ & 82,11 & 0 & 90,44 & 13,33 \\
№ de genes que controlam o caráter $(\eta)$ & 20 & - & 10 & 53 \\
\hline
\end{tabular}

${ }^{1} \mathrm{NOF}=$ número de ovos por folha; $\mathrm{NMP}=$ número de minas pequenas (comprimento $<0,5$ $\mathrm{cm}$ ); $\mathrm{NMG}=$ número de minas grandes (comprimento $\geq 0,5 \mathrm{~cm}$ ); $\mathrm{NTM}=$ número total de minas $[\mathrm{NOF}=$ number of eggs per leaf; $\mathrm{NMP}=$ number of small mines (length $<0,5 \mathrm{~cm}$ ); $\mathrm{NMG}=$ number of large mines (length $\geq 0,5 \mathrm{~cm}$ ); NTM= total number of mines].

ambientais.

Constatou-se maior número médio de ovos por folha depositados pelas fêmeas, bem como maior preferência das lagartas por alimentação (maiores nenhum caso foi superior ao valor do progenitor suscetível. A média da geração $F_{2}$ também se aproximou mais da média da 'Santa Clara' que LA 716, indicando dominância para a suscetibilidade. Nos retrocruzamentos também foram observados valores médios mais próximos do progenitor recorrente 'Santa Clara' que do doador LA 716, todavia, maior valor médio no retrocruzamento para o progenitor recorrente sempre foi observado quanto comparado com o retrocruzamento para o progenitor doador.

O número de ovos por folha indica preferência das fêmeas da traça-dotomateiro em ovipositar nas folhas das plantas. Segundo Picanço et al. (1995), o resultado dessa oviposição irá se refletir no número de minas pequenas, ou seja, quanto menor a taxa de oviposição, menor será o número de minas pequenas confeccionadas pela lagarta, o que evidência a resistência. No entanto, o número de minas pequenas, por si só, não reflete necessariamente o grau de resistência dos genótipos à praga. Elevado número de minas pequenas pode ser indicativo de não adequação do inseto à planta hospedeira, uma vez que as lagartas quando não encontram fonte alimentar adequada, se movimentam na superfície foliar em busca de alimento, 
Tabela 3. Estimativas dos parâmetros genéticos, valores de $\mathrm{R}^{2}$ e valores do coeficiente de correlação (r) entre as médias observadas ( $\left.\bar{Y}_{o}\right)$ e esperadas $\left(\bar{Y}_{e}\right)$ no modelo completo $(\mathrm{MC})$ e no modelo aditivo-dominante (MAD) para caracteres de resistência de plantas de tomate à

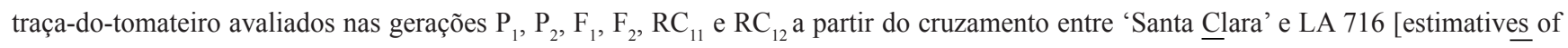
genetic parameters, values of $\mathrm{R}^{2}$ and values of coeficient of correlation (r) between the means observed $\left(\bar{Y}_{o}\right)$ and means expected $\left(\bar{Y}_{e}\right)$ for complete model (MC) and for additive-dominant model (MAD) for traits of resistance of tomato plants to tomato leafmine evaluaded in generations $\mathrm{P}_{1}, \mathrm{P}_{2}, \mathrm{~F}_{1}, \mathrm{~F}_{2}, \mathrm{RC}_{11}$ and $\mathrm{RC}_{12}$ from crossing between 'Santa Clara' and LA 716]. Viçosa, UFV, 2004.

\begin{tabular}{|c|c|c|c|c|c|c|c|c|}
\hline \multirow{3}{*}{ Parâmetro } & \multicolumn{8}{|c|}{ Caracteres de resistência $^{1}$} \\
\hline & \multicolumn{2}{|c|}{ NOF } & \multicolumn{2}{|c|}{ NMP } & \multicolumn{2}{|c|}{ NMG } & \multicolumn{2}{|c|}{ NTM } \\
\hline & MC & MAD & MC & MAD & MC & MAD & MC & MAD \\
\hline $\mathrm{m}$ & $-0,23$ & $1,30^{*}$ & $-5,97$ & $18,75^{*}$ & $9,95^{*}$ & $10,97^{*}$ & 11,44 & $26,64 *$ \\
\hline $\mathrm{a}$ & $0,36^{*}$ & $0,35^{*}$ & $14,91^{*}$ & $15,74 *$ & $6,72 *$ & $7,31^{*}$ & $23,20 *$ & $24,34 *$ \\
\hline $\mathrm{d}$ & $4,83^{*}$ & 0,45 & $72,20 *$ & 4,79 & $32,83^{*}$ & 15,45 & 45,94 & 3,30 \\
\hline aa & $1,41 *$ & - & $24,38^{*}$ & - & $-0,24$ & - & 18,26 & - \\
\hline ad & 0,37 & - & $17,25^{*}$ & - & 0,45 & - & 14,56 & - \\
\hline dd & $-3,14^{*}$ & - & $-41,31$ & - & $-29,23 *$ & - & $-18,89$ & - \\
\hline Fonte de variação & \multicolumn{8}{|c|}{ Valores de $\mathbf{R}^{2}$} \\
\hline $\mathrm{m} / \mathrm{a}, \mathrm{d}, \mathrm{aa}, \mathrm{ad}, \mathrm{dd}$ & 0,49 & - & 0,44 & - & 13,54 & - & 1,53 & - \\
\hline $\mathrm{a} / \mathrm{m}, \mathrm{d}, \mathrm{aa}, \mathrm{ad}, \mathrm{dd}$ & 17,61 & - & 74,55 & - & 47,40 & - & 87,50 & - \\
\hline $\mathrm{d} / \mathrm{m}, \mathrm{a}, \mathrm{aa}, \mathrm{ad}, \mathrm{dd}$ & 31,88 & - & 7,98 & - & 19,54 & - & 3,14 & - \\
\hline $\mathrm{aa} / \mathrm{m}, \mathrm{a}, \mathrm{d}, \mathrm{ad}, \mathrm{dd}$ & 19,44 & - & 7,64 & - & 0,01 & - & 4,21 & - \\
\hline $\mathrm{ad} / \mathrm{m}, \mathrm{a}, \mathrm{d}, \mathrm{aa}, \mathrm{dd}$ & 1,78 & - & 4,10 & - & 0,03 & - & 2,65 & - \\
\hline $\mathrm{dd} / \mathrm{m}, \mathrm{a}, \mathrm{d}, \mathrm{aa}, \mathrm{ad}$ & 28,80 & - & 5,29 & - & 19,48 & - & 0,97 & - \\
\hline $\mathrm{m} / \mathrm{a}, \mathrm{d}$ & - & 89,33 & - & 57,76 & - & 46,48 & - & 56,48 \\
\hline $\mathrm{a} / \mathrm{m}, \mathrm{d}$ & - & 7,98 & - & 41,34 & - & 30,32 & - & 43,35 \\
\hline $\mathrm{d} / \mathrm{m}, \mathrm{a}$ & - & 2,69 & - & 0,90 & - & 23,20 & - & 0,17 \\
\hline$r\left(\bar{Y}_{o}, \bar{Y}_{e}\right)$ & 1,0 & 0,82 & 1,0 & 0,96 & 1,0 & 0,75 & 1,0 & 0,98 \\
\hline
\end{tabular}

${ }^{1} \mathrm{NOF}=$ número de ovos por folha; $\mathrm{NMP}=$ número de minas pequenas (comprimento $\left.<0,5 \mathrm{~cm}\right)$; $\mathrm{NMG}=$ número de minas grandes $($ comprimento $\geq 0,5 \mathrm{~cm}) ; \mathrm{NTM}=$ número total de minas. * significativo a $5 \%$ de probabilidade pelo teste $\mathrm{t}[\mathrm{NOF}=$ number of eggs per leaf; $\mathrm{NMP}=$ number of small mines (length $<0,5 \mathrm{~cm}$ ); $\mathrm{NMG}=$ number of large mines (length $\geq 0,5 \mathrm{~cm}$ ); $\mathrm{NTM}=$ total number of mines; *significant by $\mathrm{t}$ test at $5 \%$ of probability].

confeccionando assim elevado número de minas de tamanho reduzido (Leite et al., 1995).

Suinaga et al. (2003) sugeriram que o número de minas pequenas seja avaliado em conjunto com o número de minas grandes que, se elevado, indica adequação do substrato para a alimentação das lagartas. O número de minas grandes indica, portanto, o grau de resistência ou suscetibilidade à traça-do-tomateiro. A resistência pode se refletir em maior mortalidade de pupas e adultos, redução do peso das pupas e fecundidade das fêmeas, e prolongamento das fases larval e pupal. Estes autores observaram ainda elevado número de minas pequenas e baixo número de minas grandes em acessos de L. pennellii e L. hirsutum, importantes fontes de resistência à $T$. absoluta, em comparação com cultivares de $L$. esculentum.

A não-preferência por oviposição e alimentação da traça-do-tomateiro pelas folhas da espécie silvestre $L$. pennellii (LA 716), em comparação com 'Santa Clara', evidenciou resistência do tipo antixenose possivelmente devido à presença dos acilaçúcares, que conferem resistência às pragas (Gonçalves Neto et al., 2010).

A partir das estimativas do grau médio de dominância (GMD) com base nas médias, foi constatada a dominância para a suscetibilidade, uma vez que constatou-se dominância parcial para maiores números de ovos por folha e minas pequenas, grandes e totais $(\mathrm{GMD}=0,78,0,44,0,57$ e 0,38 , respectivamente). Estes resultados corroboram com os obtidos por Resende et al. (2002) e Gonçalves et al. (2007), os quais também constataram dominância parcial para a suscetibilidade para o caráter produção de acilaçúcares, causa química da resistência de plantas de LA 716 às diversas pragas.

Comparando-se o GMD obtido por meio das variâncias e das médias, observou-se discrepância nos resultados obtidos. Segundo Ramalho et al. (1993) e Cruz et al. (2004), os valores estimados pelas variâncias, uma estatística de segunda ordem, devem ser preferidos, pois as médias, algumas vezes, podem não representar o que realmente está acontecendo, por causa de desvios de dominância positivos e negativos que podem estar se anulando. No entanto, 
devido às questões anteriormente discutidas em relação às estimativas viesadas das variâncias, acredita-se que os resultados das médias proporcionaram estimativas mais consistentes.

Embora viesadas, as estimativas de variância resultaram em estimativas de parâmetros genéticos que indicaram para número de ovos por folha e número de minas grandes que as variâncias genotípicas na população $\mathrm{F}_{2}$ foram atribuídas a efeitos aditivos, em razão das estimativas das variâncias negativas da variância devida à dominância ( $\hat{\sigma}_{D}^{2}$ $=-1,55$ e $-69,24$, respectivamente), que foram consideradas nulas para fins de cálculos. Já a variância genotípica na população $\mathrm{F}_{2}$ para número de minas pequenas foi toda atribuída aos desvios de dominância, devido à estimativa negativa da variância aditiva $\left(\hat{\sigma}_{A}^{2}=\right.$ -344,39) (Tabela 2).

As estimativas negativas de desvios de dominância ou aditividade podem ser atribuídas à baixa acurácia das estimativas da variância ambiental (valores superestimados). Segundo Carvalho et al. (2001), em estudos de análises de gerações por meio de variâncias são, geralmente, utilizados $\mathrm{P}_{1}$, $\mathrm{P}_{2}$ e $\mathrm{F}_{1}$, em diferentes expressões, para estimar a variância ambiental, devido à variação entre plantas nestas gerações ser toda devida ao ambiente. Todavia, estas gerações apresentam, de maneira geral, variância entre plantas maior que nas gerações segregantes, resultando em estimativas viesadas dos parâmetros genéticos.

Apenas para número total de minas foi possível obter estimativas positivas para todos os parâmetros baseados nas variâncias. Obteve-se $\hat{\sigma}_{A}^{2}=92,26$ e $\hat{\sigma}_{D}^{2}=471,49$, indicando que maior parte da variância genotípica total foi atribuída à variância de dominância. Como consequência, a herdabilidade no sentido restrito estimada foi baixa $(13,33 \%)$, indicando dificuldade na seleção de plantas resistentes e baixa resposta à seleção em populações segregantes. Pelo menos 53 genes controlam o caráter número total de minas (Tabela 2). Cruz et al. (2004) sugerem cautela em interpretar o número de genes que controlam o caráter em estudo com base no estimador utilizado devido às pressuposições em que se baseia, porém estes mesmos autores citam a importância das estimativas dos números de genes como indicativas da natureza poligênica ou monogênica no controle do caráter. No caso, houve indicativo de herança poligênica no controle do número total de minas.

As estimativas de herdabilidade no sentido amplo para número de ovos por folha, número de minas pequenas, número de minas grandes e número total de minas estimadas foram $72,24 \%, 86,64 \%, 86,38 \%$ e $80,87 \%$, respectivamente (Tabela 2), indicando que maior parte da variação fenotípica é atribuída a causas genéticas. Os valores estimados de herdabilidade no sentido restrito, para número de ovos por folha e número de minas grandes foram, respectivamente, 82,11 e 90,44\%, indicando grande participação da variância aditiva na variação fenotípica. Para número de minas pequenas a herdabilidade no sentido restrito foi igual a zero, devido à estimativa negativa do componente aditivo. $\mathrm{O}$ número de ovos por folha e o número de minas grandes são controlados por, no mínimo, 20 e 10 genes, respectivamente, indicando herança poligênica e maior influência ambiental.

Na Tabela 3 são apresentadas as estimativas dos parâmetros genéticos obtidos no modelo completo e no modelo aditivo-dominante. No modelo completo a média foi significativa apenas em relação ao número de minas grandes. Para todos os caracteres foi significativo o efeito aditivo. Apenas na herança do número total de minas o efeito devido à dominância não foi significativo. Interações epistáticas aditiva $\mathrm{x}$ aditiva foram importantes na herança do número de ovos por folha e número de minas pequenas; do tipo aditivo $\mathrm{x}$ dominante (ad) foram importantes na herança do número de minas pequenas, e interações epistáticas dominante $\mathrm{x}$ dominante (dd) foram importantes na herança do número de ovos por folha e número de minas grandes.

$\mathrm{O}$ efeito genético mais importante na determinação do número de ovos por folha foi devido à dominância, o qual explicou $31,88 \%$ da variabilidade disponível em $\mathrm{F}_{2}$. $\mathrm{O}$ efeito aditivo, por sua vez, foi o mais importante na determinação do número de minas grandes, número de minas pequenas e número total de minas, explicando, respectivamente, $74,55,47,40$ e $87,50 \%$ da variabilidade disponível, evidenciando que para estes caracteres é possível a obtenção de genótipos homozigóticos superiores a partir da seleção nas populações derivadas de $\mathrm{F}_{2}$ e que os ganhos nos ciclos de seleção serão satisfatórios. A correlação das médias observadas com as estimadas foi máxima para todos os caracteres $(\mathrm{r}=1,0)$, indicando o ajuste dos dados ao modelo completo.

De acordo com Cruz et al. (2004), embora o uso do modelo completo para descrever as médias das gerações seja de grande importância para o conhecimento mais abrangente das causas e magnitudes dos componentes genéticos que controlam o caráter, é importante também avaliar o modelo reduzido aditivo-dominante. Este modelo é mais simples e tem sido utilizado em programas de melhoramento, por prover informações indispensáveis na avaliação da eficiência de métodos empregados e do êxito dos mesmos.

No modelo aditivo-dominante a média e o efeito aditivo foram significativos para todos os caracteres pelo teste t a 5\% de probabilidade, sendo os efeitos mais importantes na determinação do número de ovos por folha, número de minas grandes, número de minas pequenas e número total de minas, uma vez que, pelo efeito de dominância pode-se explicar apenas $2,69,0,90,23,20$ e $0,17 \%$, respectivamente, da variação total em $\mathrm{F}_{2}$. Mediante a correlação das médias observadas com as estimadas evidenciou-se elevado ajuste do modelo aditivo-dominante para o número de minas pequenas e número total de minas, o qual possibilitou estimativas elevadas de coeficiente de correlação nos valores de 0,96 e 0,98.

Nota-se que os dados referentes ao número total de minas ajustaramse tanto ao modelo completo quanto ao modelo aditivo-dominante. Além disso, em ambos os modelos, não 
houve significância dos efeitos devido à dominância e, no caso do modelo completo, não houve também significância dos efeitos epistáticos. Assim evidencia-se a importância do uso deste caráter em programas de melhoramento que visam à obtenção de variedade resistente à traça-dotomateiro, devido à possibilidade de obtenção de plantas homozigóticas superiores a partir da seleção nas populações $\mathrm{F}_{2}$ e de ganhos satisfatórios nos ciclos de seleção, já que o componente de natureza aditiva foi um dos mais importantes.

Há indicativo de herança poligênica no controle do número de ovos por folha, número de minas grandes e número total de minas. Há dominância parcial para maior número de ovos por folha e maiores números de minas pequenas, grandes e totais. Tanto o modelo completo quanto o aditivo-dominante são apropriados ao estudo da herança do número de minas pequenas e número total de minas, sendo o efeito aditivo o mais importante na determinação dos caracteres de resistência. O número total de minas, como caráter de resistência à traça-do-tomateiro é importante em programas de melhoramento que visam à obtenção de variedade de tomate resistente.

\section{AGRADECIMENTOS}

À Universidade Federal de Viçosa e ao CNPq pela concessão de bolsa de doutorado ao primeiro autor.

\section{REFERÊNCIAS}

AGRIANUAL. 2012. Anuário da Agricultura Brasileira. São Paulo: FNP Consultoria e Comércio. 482p.

ARAGÃO CA; DANTAS BF; BENITES FRG. 2002. Efeito de aleloquímicos em tricomas foliares de tomateiro na repelência a ácaro (Tetranychus urticae Koch.) em genótipos com teores contrastantes de 2-tridecanona. Acta Botanica Brasilica 16: 83-88.

AZEVEDO SM; FARIA MV; MALUF WR; OLIVEIRA ACB; FREITAS AS. 2003. Zingiberene-mediated resistance to the South American tomato pinworm. Euphytica 134: 347-351.

BLAUTH SL; CHURCHILL GA; MATSCHLER MA. 1998. Identification of quantitative trait locos associated with acylsugar accumulation using intraspecific populations of the wild tomato, Lycopersicon pennellii. Theoretical and Applied Genetics 96: 458-467.

CARVALHO FIF; SILVA SA; KUREK AJ; MARCHIORO VS. 2001. Estimativas e implicações da herdabilidade como estratégia de seleção. Pelotas: Universitária, 99p.

CRUZ CD. 2013. GENES - a software package for analysis in experimental statistics and quantitative genetics. Acta Scientiarum Agronomy. 35: 271-276.

CRUZ CD; REGAZZI AJ. CARNEIRO PCS. 2004. Modelos biométricos aplicados ao melhoramento genético. 3ed. Viçosa: UFV, 480p.

ECOLE CC; PICANÇO MC; MOREIRA MD; MAGALHÃES STV. 2000. Componentes químicos associados à resistência de Lycopersicon hirsutum f. typicum a Tuta absoluta (Meyrick) (Lepidoptera: Gelechiidae). Anais da Sociedade Entomológica do Brasil 29: 327-337.

GALLO D; SILVEIRA NETO S; CARVALHO RPL; BAPTISTA GC; BERTI FILHO E; PARRA JRP; ZUCCHI RA; ALVES SB; VENDRAMIN JD; MARCHINI LC; LOPES JRS; OMOTO C. 2002. Entomologia agrícola. Piracicaba: FEALQ. 920p.

GONÇALVES LD; MALUF WR; CARDOSO MG; GOMES LAA; NASCIMENTO IR. 2007. Herança de acilaçúcares em genótipos de tomateiro provenientes de cruzamento interespecífico. Pesquisa Agropecuária Brasileira 42: 699-705.

GONÇALVES NETO AC; SILVA VF; MALUF WR; MACIEL GM; NÍZIO DAC; GOMES LAA; AZEVEDO SM. 2010. Resistência à traça-do-tomateiro em plantas com alto teor de acilaçúcares nas folhas. Horticultura Brasileira 28: 203-208.

LEITE GLD; PICANÇO MC; SILVA DJH; MATA AAC; JHAM GN. 1995. Distribuição de oviposição de Scrobipalpuloides absoluta no dossel de Lycopersicon esculentum, Lycopersicon hirsutum e Lycopersicon peruvianum. Horticultura Brasileira 13: 47-51.

LEMKE CA; MUTSCHLER MA. 1984. Inheritance of glandular trichomes in crosses between Lycopersicon esculentum and Lycopersicon pennellii. Journal of American Society for Horticultural Science 109: 592596.

LIETTII M; BOTTOII E; ALZOGARAY R. 2005. Insecticide resistance in Argentine populations of Tuta absoluta (Meyrick) (Lepidoptera: Gelechiidae). Neotropical Entomology 34: 113-119.

LOWSON DM; LUNDE CF; MUTSCHLER MA. 1997. Marker-assisted transfer of acylsugarmediated pest resistance from the wild tomato, Lycopersicon pennellii, to the cultivated tomato, Lycopersicon esculentum. Molecular Breeding 3: 307-317.

MEDEIROS MA; SUJII ER; RASI GC; LIZ RS; MORAIS HC. 2009. Padrão de oviposição e tabela de vida da traçado-tomateiro Tuta absoluta (Meyrick) (Lepidoptera, Gelechiidae). Revista Brasileira de Entomologia 53: 452456.

MOREIRA GR; SILVA DJH; PICANÇO MC;
PETERNELLI LA; CALIMAN FRB. 2005. Divergência genética entre acessos de tomateiro infestados por diferentes populações da traça-do-tomateiro. Horticultura Brasileira 23: 893-898.

MOREIRA GR; SILVA DJH; PICANÇO MC; PETERNELLI LA; CALIMAN FRB. 2004. Divergência genética e subcoleção representativa de populações da traça-dotomateiro. Pesquisa Agropecuária Brasileira 39: 437-443.

MUTSCHLER MA; DOERGE RW; LIU SC; KUAI JP; LIEDL BE; SHAPIRO JA. 1996. QTL analysis of pest resistance in the wild tomato Lycopersicon pennellii: QTLs controlling acylsugar level and composition. Theoretical and Applied Genetics 92: 709-718.

PICANÇO MC; SILVA DJH; LEITE GLD; MATA AC; JHAM GN. 1995. Intensidade de ataque de Scrobipalpula absoluta (Meyrick, 1917) ao dossel de três espécies de tomateiro. Pesquisa Agropecuária Brasileira 30: 429-433.

RAMALHO MAP; SANTOS JB; ZIMMERMAN MJ. 1993. Genética quantitativa em plantas autógamas. Goiânia: UFG, 271p.

RESENDE TV; MALUF WR; CARDOSO MG; NELSON DL; FARIA MV. 2002. Inheritance of acylsugar contents in tomatoes derived from a interspecific cross with the wild tomato Lycopersicon pennellii and their effect on spider mite repellence. Genetics and Molecular Research. 1: 106-116.

RESENDE JTV; MALUF WR; FARIA MV; PFANN AZ; MASCIMENTO IR. 2006. Acylsugars in tomato leaflets confer resistance to the South American tomato pinworm, Tuta absoluta Meyr. Scientia Agricola 63: 20-25.

SILVA GA; PICANÇO MC; BACCI L; CRESPO AL; ROSADO JF; GUEDES RN. 2011. Control failure likelihood and spatial dependence of insecticide resistance in the tomato pinworm, Tuta absoluta. Pest Management Science 67: 913-920.

SHAPIRO JA; STEFFENS JC; MUTSCHLER MA. 1994. Acylsugars of the wild tomato Lycopersicon pennellii in relation to geographic distribution of the species. Biochemical Systematics and Ecology 22: 545- 561.

SUINAGA FA; CASALI VWD; PICANÇO MC; SILVA DJH. 2004. Capacidade combinatória de sete caracteres de resistência de Lycopersicon spp. à traça-do-tomateiro. Horticultura Brasileira 22: 243-248.

SUINAGA FA; CASALI VWD; SILVA DJH; PICANÇO MC. 2003. Dissimilaridade genética de fontes de resistência de Lycopersicon spp. a Tuta absoluta (Meyrick, 1917) (Lepidoptera: Gelechiidae). Pesquisa Agropecuária Brasileira 9: 371-376.

TAYLOR B. 1986. Biosistematics of the tomato. In: ATHERTON JG; RUDICH J. The tomato crop: a scientific basis for improvement. New York: Champman and Hall, p.1-30.

VALOIS ACC; NASS LL; GOES M. 2001. Conservação ex situ de recursos genéticos vegetais. In: NASS LL; VALOIS ACC; MELO IS; VALADARES-INGLIS MC (eds) Recursos genéticos e melhoramento-plantas. Rondonópolis: Fundação MT, p. 124-147. 